*Section of Pulmonary Medicine, ${ }^{\S}$ Dept of Pathology, Ioannina University Hospital, "Pulmonary Dept "G. Hatzikosta" General Hospital, Depts of "Hygiene and Epidemiology, and ${ }^{+}$Anatomy, University of Ioannina, Ioannina, Greece.

Correspondence: S.H. Constantopoulos, Dept of Medicine, Section of Pulmonary Medicine, Medical School, University of Ioannina, Ioannina 45500, Greece. E-mail: eprevezi@uoi.gr

Statement of Interest: None declared.

\section{REFERENCES}

1 Hillerdal G. Mesothelioma: cases associated with non-occupational and low dose exposures. Occup Environ Med 1999; 56: 505-513.

2 Constantopoulos SH. Environmental mesothelioma associated with tremolite asbestos: lessons from the experiences of Turkey, Greece, Corsica, New Caledonia and Cyprus. Regul Toxicol Pharmacol 2008; 52: $110-115$.

3 Baris YI, Simonato M, Artvinli M, et al. Epidemiological and environmental evidence of the health effects of exposure to erionite fibres: a four year study in the Cappadocian region of Turkey. Int $J$ Cancer 1987; 39: 10-17.
4 Constantopoulos SH, Malamou-Mitsi V, Goudevenos JA, et al. High incidence of malignant pleural mesothelioma in neighbouring villages of Northwest Greece. Respiration 1987; 51: 266-271.

5 Constantopoulos SH, Goudevenos JA, Saratzis NA, et al. Metsovo lung: pleural calcifications and restrictive lung function in NorthWestern Greece; environmental exposure to mineral fiber as etiology. Environ Res 1985; 38: 319-331.

6 Langer AM, Nolan RP, Constantopoulos SH, et al. Association of Metsovo lung and pleural mesothelioma with exposure to tremolite-containing whitewash. Lancet 1987; 1: 965-967.

7 Constantopoulos SH, Saratzis NA, Goudevenos JA, et al. Tremolite white-washing and pleural calcifications. Chest 1987; 92: 709-712.

8 Sakellariou K, Malamou-Mitsi V, Haritou A, et al. Malignant pleural mesothelioma from non-occupational asbestos exposure in Metsovo (North West Greece); slow end of an epidemic? Eur Respir J 1996; 9: 1206-1210.

9 Senyiğit A, Babayiğit C, Gökirmak M, et al. Incidence of malignant pleural mesothelioma due to environmental asbestos fiber exposure in the southeast of Turkey. Respiration 2000; 67: 610-614.

10 Darcey DJ, Alleman T. Occupational and environmental exposure to asbestos. In: Roggli VL, Oury TD, Sporn ThA, eds. Pathology of Asbestos-Associated Diseases. 2nd Edn. Springer, New York, 2004; pp. 17-33.

\title{
An audit of hypoxaemia, hyperoxaemia, hypercapnia and acidosis in blood gas specimens
}

\section{To the Editors:}

The emergency management of hypoxaemic patients requires clinicians to avoid the hazard of dangerous hypoxaemia due to under-treatment with oxygen, whilst also avoiding the hazards of hypercapnic respiratory failure (iatrogenic hypercapnia) and oxygen toxicity, which may be caused by over-treatment with oxygen. In the past, many clinicians acted cautiously by giving high concentrations of oxygen to all potentially hypoxaemic patients and a culture evolved that "more is better". However, since the 1960s, it has been known that some patient groups, particularly those with chronic obstructive pulmonary disease (COPD), are especially vulnerable to uncontrolled oxygen therapy and a recent randomised study showed that mortality in this patient group was doubled when high-concentration oxygen was used compared with controlled oxygen therapy [1-4]. It has also been demonstrated that hyperoxaemia is associated with increased mortality in patients with stroke, and in survivors of cardiac resuscitation and critically ill patients in the intensive care unit (ICU) [5-7]. The British Thoracic Society (BTS) guidelines for emergency oxygen use recommend a target oxygen saturation range of $94-98 \%$ for most emergency medical patients and a lower target range of $88-92 \%$ for those at risk of hypercapnic respiratory failure [8]. The proportion of emergency medical patients for whom each target range is appropriate is not known but a recent study of 1,022 emergency ambulance patients in the UK reported that $4 \%$ of ambulance patients had exacerbated COPD as the main diagnosis and $5.5 \%$ of non-COPD patients had saturation $<90 \%$ at some time during the ambulance journey [9].
We studied an anonymised database consisting of blood gas analysis results from 3,524 specimens sent to the Biochemistry Laboratory of the Salford Royal University Hospital (Salford, UK) between June and November 2007. More than 95\% of samples were from adult patients (neonatal and paediatric samples were analysed separately). About $5 \%$ of samples were arterialised earlobe capillary samples. Most emergency department and ICU samples were analysed on separate blood gas analysers and were not included in this analysis. The results are summarised in table 1 . The saturation bands were chosen to correspond with the recommended target saturation ranges in the BTS guidelines, in addition to saturation bands above, below and between these ranges. The majority of patients were receiving oxygen therapy at the time of sampling. 2,693 samples had information about the inspired oxygen concentration, of which $19 \%$ were said to be breathing air at the time of sampling and $81 \%$ were on oxygen therapy ranging $24-100 \%$.

More than a quarter of samples (26.9\%) demonstrated hypercapnia with carbon dioxide tension $\left(\mathrm{PCO}_{2}\right)>6.0 \mathrm{kPa}$ or $45 \mathrm{mmHg}$ consistent with type 2 respiratory failure, but only $198(5.6 \%)$ samples had evidence of type 1 respiratory failure (oxygen tension $\left(\mathrm{PO}_{2}\right)<8.0 \mathrm{kPa}$ or $60 \mathrm{mmHg}$ with normal $\left.\mathrm{PCO}_{2}\right)$. Detailed results are summarised in table 1.

$1,458(41.3 \%)$ samples had oxygen saturation $>98 \%$ and 1,074 samples $\left(30 \%\right.$ of all samples) were hyperoxaemic with $\mathrm{PO}_{2}$ $>15.0 \mathrm{kPa}$ (112 $\mathrm{mmHg}$ ), which is the upper limit of normal in our laboratory at the Salford Royal University Hospital. 
TABLE 1 Summary of blood gas results grouped according to oxygen saturation levels

\begin{tabular}{|c|c|c|c|c|c|}
\hline Oxygen saturation range & Samples & Hypercapnia\# & $\begin{array}{l}\text { Uncompensated } \\
\text { respiratory acidosis" }\end{array}$ & $\begin{array}{l}\text { Compensated } \\
\text { respiratory acidosis }\end{array}$ & $\begin{array}{l}\text { Uncompensated } \\
\text { metabolic acidosis }\end{array}$ \\
\hline $94-98 \%$ & $1291(36.6)$ & $294(23)$ & $65(5)$ & $167(13)$ & $90(7)$ \\
\hline $92.1-93.9 \%$ & $237(6.7)$ & $85(36)$ & $14(6)$ & $58(24)$ & $15(6)$ \\
\hline $88-92 \%$ & 288 (8.2) & $119(41)$ & 35 (12) & $61(21)$ & 17 (6) \\
\hline $60-69.9 \%$ & $22(0.6)$ & $14(64)$ & $6(27)$ & $4(18)$ & $4(18)$ \\
\hline$<60 \%$ & $21(0.6)$ & $15(71)$ & $6(29)$ & $5(24)$ & $2(10)$ \\
\hline Total & 3524 (100) & 948 (26.9) & 239 (6.8) & $518(14.7)$ & $246(7.0)$ \\
\hline
\end{tabular}

Data are presented as $n$ (\%). 94-98\% is the suggested target range for the majority of acutely unwell patients and $88-92 \%$ is the suggested target range for those at risk of hypercapnic respiratory failure [6]. ${ }^{\#}$ : carbon dioxide tension $\left(\mathrm{PCO}_{2}\right)>6.0 \mathrm{kPa}$ or $45 \mathrm{mmHg} . " \mathrm{pH}<7.35, \mathrm{PCO}_{2}>6.0 \mathrm{kPa}$ or $45 \mathrm{mmHg}$, and normal or elevated base excess. Includes 140 samples with uncompensated respiratory acidosis (base excess -2.0 to $+2.0 \mathrm{mmol} \cdot \mathrm{L}^{-1}$ ) and 99 samples with incompletely compensated respiratory acidosis ( $\mathrm{pH}$ remains $<7.35$ despite base excess $\left.>2.0 \mathrm{mmol} \cdot \mathrm{L}^{-1}\right)$. ${ }^{+}$: compensated respiratory acidosis $\left(\mathrm{pH} 7.35-7.45, P \mathrm{CO}_{2}>6.0 \mathrm{kPa}\right.$ or $45 \mathrm{mmHg}$, and base excess $\left.>2.0 \mathrm{mmol} \cdot \mathrm{L}^{-1}\right)$. ${ }^{\mathrm{s}}$ : uncompensated metabolic acidosis $\left(\mathrm{pH}<7.35, \mathrm{PCO}_{2} \leqslant 6.0 \mathrm{kPa}\right.$ or $45 \mathrm{mmHg}$, and base excess $\left.<-2.0 \mathrm{mmol} \cdot \mathrm{L}^{-1}\right)$. $65(1.8 \%)$ samples demonstrated mixed metabolic and respiratory acidosis ( $\mathrm{pH}<7.35, \mathrm{PCO}_{2}>6.0 \mathrm{kPa}$ or $45 \mathrm{mmHg}$, and base excess $\left.<-2.0 \mathrm{mmol} \cdot \mathrm{L}^{-1}\right)$.

$362(10 \%)$ samples were grossly hyperoxaemic with $\mathrm{PO}_{2}$ $\geqslant 20 \mathrm{kPa}(\geqslant 150 \mathrm{mmHg}) .362(10.2 \%)$ samples had oxygen saturation $<90 \%$ but only $2.7 \%$ were severely hypoxaemic with oxygen saturation $<80 \%$, and the majority of these samples exhibited hypercapnia with respiratory acidosis, indicating a need for either cautious oxygen therapy or ventilatory support.

The oxygen saturation was above the recommended target range for hypercapnic patients (saturation $>92 \%$ ) in $72 \%$ of our hypercapnic samples. $21.5 \%$ of all samples had findings consistent with respiratory acidosis $(6.8 \%$ uncompensated and $14.7 \%$ compensated; table 1 ). Of the 239 patients with uncompensated respiratory acidosis, 59\% had a normal base excess measurement consistent with acute respiratory acidosis and $41 \%$ had an elevated base excess $\left(>2.0 \mathrm{mmol} \cdot \mathrm{L}^{-1}\right)$ consistent with chronic respiratory acidosis, although a proportion of these patients would have had acute decompensation of chronic respiratory acidosis.

Although it can be assumed that blood gas samples are usually taken from hospital patients at the highest risk of hypoxaemia, these results demonstrate that severe uncorrected hypoxaemia was relatively uncommon in this large database compared with the high prevalence of iatrogenic hyperoxaemia and hypercapnia, both of which may be associated with increased mortality [1-8]. Because the data were anonymised, the inspired oxygen concentration could not be validated and it was not possible to review the results by disease group or by outcome. For example, it is likely that some of the most hypoxaemic and acidotic specimens were collected during unsuccessful cardiac arrest procedures or from patients who were close to the end of their life. Additionally, it is likely that there were many repeat blood gas samples from the sickest patients with low blood oxygen levels.

This preliminary study suggests that severe uncorrected hypoxaemia with oxygen saturation $<80 \%$ is relatively uncommon in modern hospital practice ( $2.7 \%$ of samples in this survey) and 54 of the 96 severely hypoxaemic samples had respiratory acidosis, whilst only seven of these samples had evidence of metabolic acidosis, which might be an expected consequence of severe hypoxaemia. Although severe hypoxaemia was uncommon, hyperoxaemia ( $30 \%$ of samples), hypercapnia ( $27 \%$ of samples) and respiratory acidosis (21\% of samples) were relatively common findings and we found that hypercapnic (type 2) respiratory failure was five times more common than pure hypoxaemia (type 1 respiratory failure). These findings suggest that oxygen needs to be used with more caution in hospitals, particularly as it has recently been reported that hyperoxaemia in ICUs (arterial oxygen tension $\mathrm{Pa}_{\mathrm{a}_{2}}>16 \mathrm{kPa}$ or $120 \mathrm{mmHg}$ ) was associated with higher mortality than hypoxaemia $\left(\mathrm{Pa}_{1} \mathrm{O}_{2}<9 \mathrm{kPa}\right.$ or $67 \mathrm{mmHg}$ ) [7]. Our findings do not support the view of some clinicians that more patients are at risk of harm from lack of oxygen than from too much oxygen [10]. We now plan to seek permission to conduct a prospective study, which will involve review of diagnosis and outcome for each patient.

\section{B.R. O'Driscoll*, A. Rudenski*, P.M. Turkington* and L.S. Howard ${ }^{\#}$}

*Manchester Academic Health Science Centre, University of Manchester, Salford Royal University Hospital, Salford, and "Dept of Respiratory Medicine, Hammersmith Hospital, Imperial College Healthcare NHS Trust, London, UK.

Correspondence: B.R. O'Driscoll, Manchester Academic Health Science Centre, University of Manchester, Salford Royal University Hospital, Stott Lane, Salford, M6 8HD, UK. E-mail: ronan.o'driscoll@srft.nhs.uk

Statement of Interest: None declared.

\section{REFERENCES}

1 Campbell EJ. The J. Burns Amberson Lecture. The management of acute respiratory failure in chronic bronchitis and emphysema. Am Rev Respir Dis 1967; 96: 626-639. 
2 Hutchison DC, Flenley DC, Donald KW. Controlled oxygen therapy in respiratory failure. BMJ 1964; 2: 1159-1166.

3 Austin MA, Wills KE, Blizzard L, et al. Effect of high flow oxygen on mortality in chronic obstructive pulmonary disease patients in prehospital setting: randomised controlled trial. BMJ 2010; 341: c5462.

4 O'Driscoll BR, Beasley R. Avoidance of high concentration oxygen in chronic obstructive pulmonary disease. BMJ 2010; 341: c5549.

5 Rønning OM, Guldvog B. Should stroke victims routinely receive supplemental oxygen? A quasi-randomized controlled trial. Stroke 1999; 30: 2033-2037.

6 Kilgannon JH, Jones AE, Shapiro NI, et al. Association between arterial hyperoxia following resuscitation from cardiac arrest and in-hospital mortality. JAMA 2010; 303: 2165-2171.

7 de Jonge E, Peelen L, Keijzers PJ, et al. Association between administered oxygen, arterial partial oxygen pressure and mortality in mechanically ventilated intensive care unit patients. Crit Care 2008; 12: R156.

8 O'Driscoll BR, Howard LS, Davison AG. British Thoracic Society Guideline for emergency oxygen use in adult patients. Thorax 2008; 63: Suppl. 6, 1-68.

9 Hale KE, Gavin C, O'Driscoll BR. An audit of oxygen use in emergency ambulances and in a hospital emergency department. Emerg Med J 2008; 25: 733-736.

10 O'Leary MJ. Re: Oxygen therapy in COPD. www.bmj.com/ content/341/bmj.c5549/reply. Date last updated: November 9, 2010. Date last accessed: October, 26: 2011.

\section{Cat litter is a possible trigger for sarcoidosis}

\section{To the Editors:}

Sarcoidosis is characterised by cellular immune activity with noncaseating granuloma formation in various organ systems with a multifactorial cause. Many causative agents are considered to be involved in the pathogenesis [1-5]. Geneenvironment interactions offer the potential for strengthening the evidence of causation between exposures and sarcoidosis. It is important to identify every potential exposure to triggers in order to avoid irreversible damage. Inorganic agents, including silica, have been reported to initiate inflammation and granulomatous reactions $[6,7]$. It is well known that cats can cause allergic reactions, but less is known about the association of inflammation and cat litter. We propose that silica, the major component of cat litter, might be such an agent. We report a case of biopsy-proven sarcoidosis with birefringent material, mainly silica, within the lung biopsy specimen. The patient had no relevant occupational history, but had cats and was extensively exposed to silica-containing cat litter. Initially, the patient improved after starting immunosuppressive drugs and terminating contact with litter. However, she deteriorated twice after autoprovocation (re-exposure) to cat litter. After changing the silica-containing cat litter for litter without silica, her clinical condition improved substantially. Obviously, she appeared to be "hypersensitive" not to the cats but to the cat litter.

A 44-yr-old female was admitted to the former ILD Care Team (a tertiary referral centre) of the Dept of Respiratory Medicine, Maastricht University Medical Centre (Maastricht, the Netherlands). The patient had been diagnosed with sarcoidosis 4 yrs prior to admission. She had no medical history and did not smoke or use any medication. The diffusing capacity of the lung for carbon monoxide was impaired (62\% predicted). A chest radiograph demonstrated a micronodular interstitial pattern without enlargement of lymph nodes (stage III), and was confirmed by a high-resolution computed tomography (CT) scan. Inflammatory signs of sarcoidosis were increased, including angiotensin-converting enzyme (ACE) (30 U. $\mathrm{L}^{-1}$, normal range $9-25 \mathrm{U} \cdot \mathrm{L}^{-1}$ ) and soluble interleukin-2 receptor (sIL-2R) $\left(4,518 \mathrm{pg} \cdot \mathrm{mL}^{-1}\right.$, reference range $\left.240-3,154 \mathrm{pg} \cdot \mathrm{mL}^{-1}\right)$, and a wholebody ${ }^{18} \mathrm{~F}$-2-fluoro-2-deoxy-D-glucose (FDG) positron emission tomography (PET)/CT scan demonstrated uptake in the lung parenchyma and spleen indicative of sarcoidosis inflammatory activity. Bronchoalveolar lavage fluid analysis revealed a cellular pattern compatible with sarcoidosis (a lymphocytosis of $26 \%$ ) [8]. A lung biopsy showed granulomas consistent with sarcoidosis with birefringent material. A detailed history excluded occupational or environmental exposure to silica. However, she had eight cats and four of them were sleeping in two cat boxes in her bedroom. Treatment with prednisone was started. As her clinical situation did not improve after 2 months, methotrexate (MTX) (12.5 mg once a week orally with $5 \mathrm{mg}$ folic acid once a week, taken on a different day to the MTX) was added. We also advised her to temporarily avoid any contact with the cats, especially the cat litter.

The patient's clinical condition improved dramatically within 6 months, and we were able to taper off the prednisone and finally stop the MTX after $1 \mathrm{yr}$ of treatment. At that time, ACE $\left(20 \mathrm{U} \cdot \mathrm{L}^{-1}\right)$ and $\mathrm{sIL}-2 \mathrm{R}\left(2,361 \mathrm{pg} \cdot \mathrm{L}^{-1}\right)$ were within normal limits. Moreover, a control PET/CT scan was negative. As she felt much better, she decided to take back her cats and 2 months later, her clinical situation deteriorated and all earlier signs of sarcoidosis activity returned. Since she adored her cats so much, we advised her to search for silica-free cat litter. She found a cat litter made out of old newspapers, without silica and that was not dusty. Shortly after starting to use this, she felt much better. She was stable for almost 2 yrs without any sign of inflammation associated with sarcoidosis. Thereafter, she visited her son for 3 weeks. He has three cats and the "wrong" cat litter. 1 month later, she deteriorated again and blamed herself for not having the foresight to ask him to replace his cat litter with her own (nonsilica) brand.

Sarcoidosis susceptibility depends on both environmental and genetic modifiers $[1,4,5]$. Inflammation in sarcoidosis is characterised by ongoing T-cell and macrophage activity and granuloma formation reflected by an increase of serological markers of inflammation or abnormality in glucose metabolism demonstrated as high uptake on ${ }^{18} \mathrm{~F}-\mathrm{FDG}$ PET/CT $[4,9]$. Moreover, the endogenous antioxidant defence was found to be significantly reduced in sarcoidosis, indicating that oxidative 